\title{
The SPectrometer for Ice Nuclei (SPIN): an instrument to investigate ice nucleation
}

\author{
Sarvesh Garimella ${ }^{1}$, Thomas Bjerring Kristensen ${ }^{2}$, Karolina Ignatius $^{2}$, Andre Welti ${ }^{2}$, Jens Voigtländer ${ }^{2}$, \\ Gourihar R. Kulkarni ${ }^{3}$, Frank Sagan ${ }^{4}$, Gregory Lee Kok ${ }^{4}$, James Dorsey ${ }^{5}$, Leonid Nichman ${ }^{5}$, \\ Daniel Alexander Rothenberg ${ }^{1}$, Michael Rösch ${ }^{1}$, Amélie Catharina Ruth Kirchgäßner ${ }^{6}$, Russell Ladkin ${ }^{6}$, Heike Wex $^{2}$, \\ Theodore W. Wilson ${ }^{7}$, Luis Antonio Ladino ${ }^{8}$, Jon P. D. Abbatt ${ }^{8}$, Olaf Stetzer ${ }^{9}$, Ulrike Lohmann ${ }^{10}$, Frank Stratmann ${ }^{2}$, \\ and Daniel James Cziczo ${ }^{1}$ \\ ${ }^{1}$ Department of Earth, Atmospheric and Planetary Sciences, Massachusetts Institute of Technology, Cambridge, MA, USA \\ ${ }^{2}$ Leibniz Institute for Tropospheric Research, Leipzig, Germany \\ ${ }^{3}$ Pacific Northwest National Laboratory, Richland, WA, USA \\ ${ }^{4}$ Droplet Measurement Technologies, Boulder, CO, USA \\ ${ }^{5}$ School of Earth, Atmospheric and Environmental Sciences, University of Manchester, Manchester, UK \\ ${ }^{6}$ British Antarctic Survey, Cambridge, UK \\ ${ }^{7}$ School of Earth and Environment, University of Leeds, Leeds, UK \\ ${ }^{8}$ Department of Chemistry, University of Toronto, Toronto, Canada \\ ${ }^{9}$ V-ZUG AG, Zurich, Switzerland \\ ${ }^{10}$ Department of Environmental Systems Science, Swiss Federal Institute of Technology, Zurich, Switzerland
}

Correspondence to: Daniel James Cziczo (djcziczo@mit.edu)

Received: 21 December 2015 - Published in Atmos. Meas. Tech. Discuss.: 1 February 2016

Revised: 6 May 2016 - Accepted: 15 June 2016 - Published: 6 July 2016

\begin{abstract}
The SPectrometer for Ice Nuclei (SPIN) is a commercially available ice nucleating particle (INP) counter manufactured by Droplet Measurement Technologies in Boulder, CO. The SPIN is a continuous flow diffusion chamber with parallel plate geometry based on the Zurich Ice Nucleation Chamber and the Portable Ice Nucleation Chamber. This study presents a standard description for using the SPIN instrument and also highlights methods to analyze measurements in more advanced ways. It characterizes and describes the behavior of the SPIN chamber, reports data from laboratory measurements, and quantifies uncertainties associated with the measurements. Experiments with ammonium sulfate are used to investigate homogeneous freezing of deliquesced haze droplets and droplet breakthrough. Experiments with kaolinite, NX illite, and silver iodide are used to investigate heterogeneous ice nucleation. SPIN nucleation results are compared to those from the literature. A machine learning approach for analyzing depolarization data from the SPIN optical particle counter is also presented (as an advanced
\end{abstract}

use). Overall, we report that the SPIN is able to reproduce previous INP counter measurements.

\section{Introduction}

Aerosol particles facilitate the nucleation of cloud droplets and ice crystals in Earth's atmosphere (Pruppacher and Klett, 1997). Ice nucleating particles (INPs) enable the formation of ice crystals via several possible mechanisms, including deposition nucleation, immersion freezing, and contact freezing (Rogers, 1988; Pruppacher and Klett, 1997). Droplets freeze homogeneously below temperatures of $\sim-38^{\circ} \mathrm{C}$, including deliquesced haze droplets which do so below water saturation at such cold temperatures (Koop et al., 2000). Because of the complexity of the ice nucleation process, understanding INP interactions with water has been difficult (Hoose and Möhler, 2012; Boucher et al., 2013; Stocker et al., 2013). Despite this difficulty, the significant influence that mixed-phase clouds and ice clouds have on the Earth's radiative budget 
and hydrologic cycle makes understanding the microphysics of cloud formation an important step in quantifying their influence on climate (e.g., Storelvmo et al., 2011; Hoose and Möhler, 2012; Tao et al., 2012; Gettelman et al., 2012).

Laboratory measurements allow for the investigation of ice nucleation at specific conditions with controlled aerosol properties and provide insight into ice formation as it occurs in the atmosphere. Several types of instruments have been developed to measure the efficiency of heterogeneous nucleation of cloud droplets and ice crystals. Many of these have applicability for measurements in the laboratory, as well as intended application for field observations. Among these instruments, the Continuous Flow Diffusion Chamber (CFDC) (Rogers, 1988) has proven to be a useful tool to measure the conditions required to nucleate ice crystals on various INPs. Studies have been conducted on different nucleation and freezing mechanisms using many types of aerosol particles under a wide range of temperatures and relative humidities (RHs) (Rogers, 1988; Salam et al., 2008; Stetzer et al., 2008). Improved versions of the original cylindrical chamber described by Rogers (1988) have been successfully deployed in ground- and aircraft-based field campaigns (Chen et al., 1998; DeMott et al., 2003a, b). One contemporary (parallel plate) design is the Zurich Ice Nucleation Chamber (ZINC) (Stetzer et al., 2008), which has been used for several laboratory studies (e.g., Welti et al., 2009, 2014). The Portable Ice Nucleation Chamber (PINC), designed as a field-deployable version of the ZINC, has since been used to conduct several laboratory and field studies (Chou et al., 2011, 2013; Kanji et al., 2013). In addition, other research groups have also developed similar chambers (Kanji et al., 2009; Kulkarni et al., 2009; Friedman et al., 2013; Jones et al. 2011; Saito et al., 2011). Adapting the parallel plate design and other features from the ZINC and PINC chambers, the SPectrometer for Ice Nuclei (SPIN) is a commercially available ice nuclei counter manufactured by Droplet Measurement Technologies (DMT) in Boulder, CO. This study characterizes the behavior of the SPIN chamber and reports data that characterize the general instrument design and performance.

\section{Instrument theory and design}

\subsection{Operating principles}

CFDCs, such as the SPIN, are used for ice nucleation measurements by exposing aerosol particles to controlled temperature and RH conditions. The chamber walls (which are parallel plates in the SPIN chamber) are coated with a thin layer of ice $(\sim 1 \mathrm{~mm}$ thickness in the SPIN chamber, as inferred from the volume depleted from the water reservoir after icing). The water vapor partial pressure directly adjacent to the ice wall is the saturation vapor pressure over ice at the given ice wall temperature. A laminar air stream flows between the plates, and if the plate temperatures are different, water vapor and heat diffuse from the warmer to the colder wall. This idealized setup leads to linear profiles of water vapor partial pressure and temperature between the two walls. The exponential dependence of saturation vapor pressure on temperature, according to the Clausius-Clapeyron relation, leads to supersaturated conditions with respect to ice between the two walls, with a maximum close to the position of the aerosol lamina (Rogers, 1988; Stetzer et al., 2008). Aerosol particles are constrained within this lamina and surrounded by two sheath flows passed along each wall. This restricts the aerosol to a narrow range of temperature and supersaturation at which ice nucleation can take place. An example of the chamber flow and thermodynamic profile is shown in Fig. 1.

A sufficient temperature gradient between the walls results in the water vapor partial pressure in the aerosol lamina exceeding the saturation vapor pressure over liquid water. In this case, droplets, in addition to ice, can nucleate on the aerosol particles. Though droplets can be identified using a depolarization optical particle counter (OPC) (such as the SPIN detector described in Sect. 2.2), increasing the size difference between droplets and ice helps in distinguishing the two phases. To accomplish this, CFDC chambers employ an evaporation section after the main chamber (Fig. 2) to shrink or eliminate droplets while retaining ice crystals. The ice walls in the evaporation section of the chamber are isothermal so the water vapor partial pressure is equal to the saturation vapor pressure over ice. Droplets are therefore unstable and shrink in a manner akin to the BergeronWegner-Findeisen process (Rogers, 1988; Pruppacher and Klett, 1997). Depending on their residence time in the evaporation section, droplets over a critical size will not evaporate completely and are large enough to be detected by the OPC. The main chamber conditions that generate droplets over this critical size are termed droplet breakthrough. These conditions are quantified for the SPIN chamber in experiments described in Sect. 4 and represent an upper RH limit for ice nucleation experiments if droplets and ice crystals are indistinguishable.

\subsection{SPIN chamber design}

Figure 3 shows a diagram of the SPIN system, illustrating the refrigeration, air flow control, and water flow control components. The temperatures of the two chamber walls and the evaporation section are controlled using compressor-driven refrigeration systems and heater strips affixed to the walls. The warm wall and evaporation section are cooled using a single-stage (with R404A refrigerant) refrigeration loop, while the cold wall is cooled using a two-stage (with R404A first stage refrigerant and R508B second stage refrigerant) refrigeration loop. Ten solenoid valves (four for the warm wall, four for the cold wall, and two for the evaporation section) with proportional-integral-derivative (PID) control are used to regulate refrigeration. Thirty $30 \mathrm{~W}$ heater strips (12 on the 


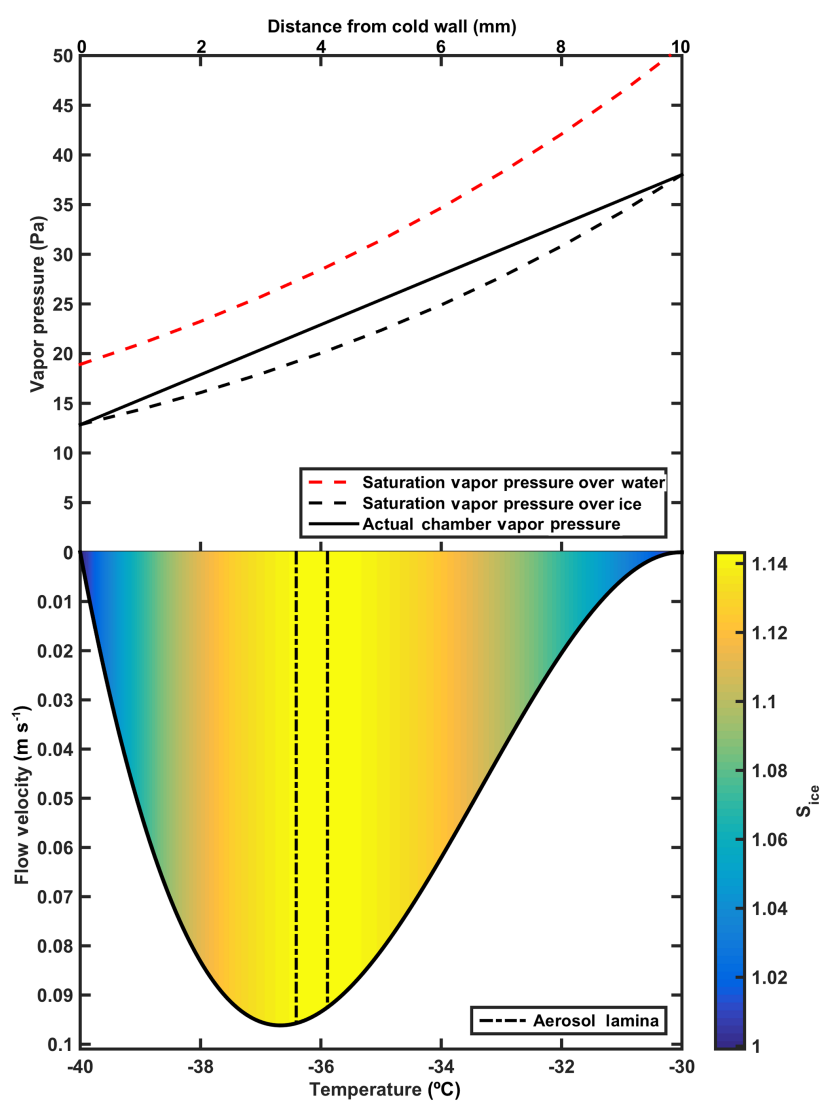

Figure 1. Representation of idealized chamber thermodynamic and flow conditions with a chamber width of $1 \mathrm{~cm}$. The chamber cold wall (left) temperature is $-40^{\circ} \mathrm{C}$ and chamber warm wall (right) is $-30^{\circ} \mathrm{C}$. The top half of the figure shows the saturation vapor pressures over ice (black dashed line), over water (red dashed line), and chamber vapor pressure (solid black line) for $10 \mathrm{~L} \mathrm{~min}^{-1}$ sheath $+1 \mathrm{~L} \mathrm{~min}^{-1}$ sample flow. Note the chamber is supersaturated everywhere with respect to ice but subsaturated with respect to water. The bottom half of the figure shows the flow velocity profile with the aerosol lamina given by the black dashed dotted lines. The colors show the horizontal variation in the ice saturation ratio across the width of the chamber. The asymmetry in the flow profile is a result of the buoyant displacement of the flow towards the cold wall.

warm wall, 12 on the cold wall, and 6 on the evaporation section) are used to minimize deviations of temperature from the set point by applying heating via 26 independent PID controllers ( 12 for each of the warm and cold walls and 2 for the evaporation section). T-type thermocouples that are inserted into the walls and affixed with thermal epoxy are positioned at 16 locations on each chamber wall and two locations on the evaporation section to map variability in temperature (Fig. 2). The chamber itself is machined from aluminum components, with the inner chamber walls sandblasted for wettability, and junctions are sealed with rubber gaskets. The plate-to-plate distance in the un-iced chamber is $1 \mathrm{~cm}$, which is reduced on average to $\sim 8 \mathrm{~mm}$ with the ice layer. Qualitative inspec-

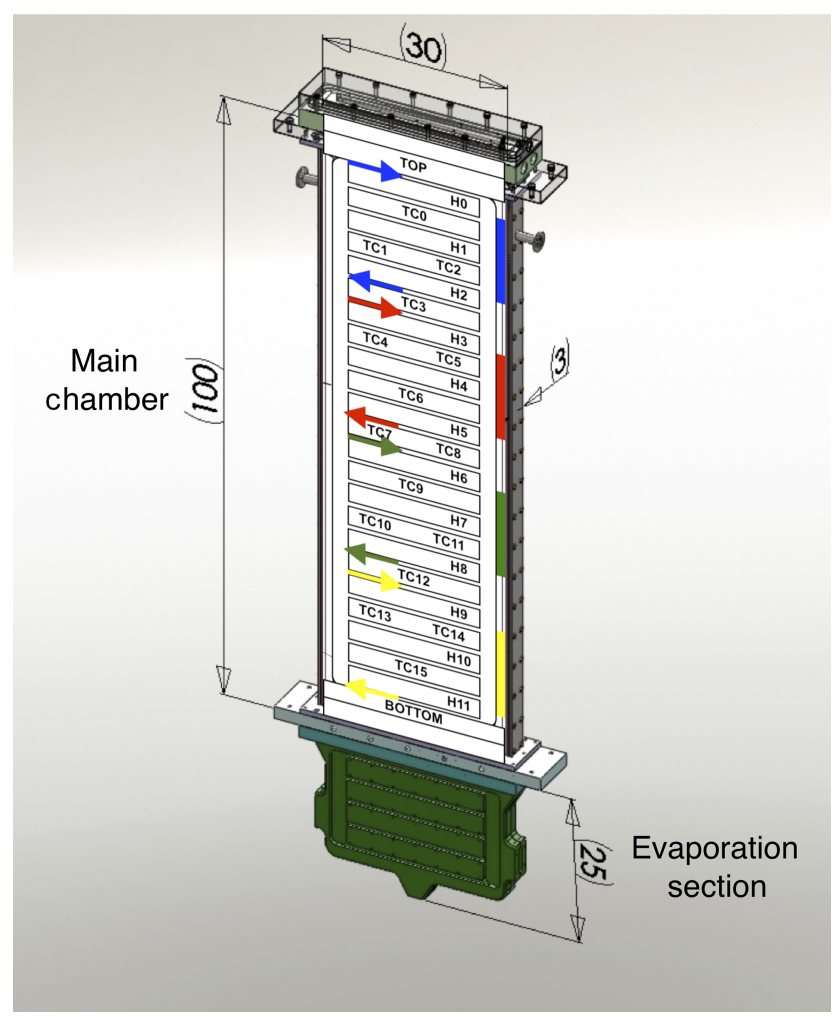

Figure 2. SPIN chamber schematic showing dimensions of the chamber with overlaid thermocouple (TC0-TC15), heater ( $\mathrm{H} 0-$ H11), and refrigeration zone (colored arrows and blocks) locations on the main chamber. Heater strips span the length of the chamber wall at each indicated location. The different colored arrows represent different refrigerant paths depending on which of the four refrigeration solenoid valves are open. All dimensions are in centimeters.

tion with an endoscope camera indicates that the ice layer is thicker towards the bottom of the chamber and thinner towards the top. The ratio of the main chamber length to the evaporation section length is $4: 1$.

A hepa-filtered and dried (using molecular sieve desiccant) sheath flow along each wall is circulated through the chamber using a pump and mass flow controller. Sample air is drawn into the system by an additional pump. The incoming sample air is drawn into the sheath flow using a knife-edge inlet similar to the one used in the ZINC (Stetzer et al., 2008), which splits the sheath into two flows that move along each wall. The knife-edge inlet also focuses the particle flow to the center of the chamber, which in laminar flow conditions, limits the temperature and supersaturation range experienced by the particles. Figure 2 shows the dimensions of the main chamber and evaporation section.

After passing through the main chamber and evaporation section, the air stream flows through a linear depolarization OPC that uses four optical detectors for counting, sizing, and differentiating unactivated aerosol particles, droplets, and ice 


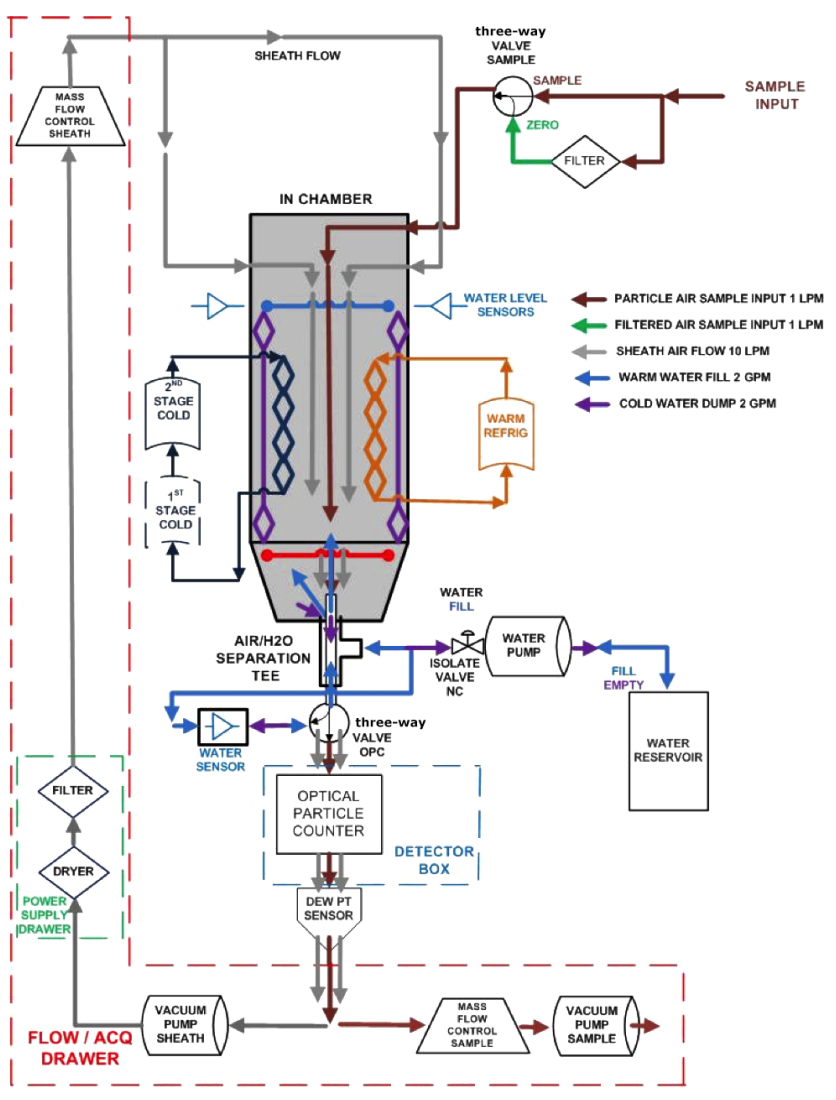

Figure 3. Air and water flow diagram for the SPIN chamber.

crystals in the $0.4-15 \mu \mathrm{m}$ size range. Figure 4 shows the optical diagram of the OPC. The side scatter detector is used for particle sizing by total scattering intensity, and the backscatter detectors are used to measure $P$ (parallel to the incident laser light) and $S$ (perpendicular to the incident laser light) polarization for phase discrimination: ice crystals depolarize more light than water droplets because of anisotropy of ice compared to liquid water (e.g., Wettlaufer et al., 1999; Thomson et al., 2009), and this change in depolarization signal is used to differentiate the two phases (Liou and Lahore, 1974; Nicolet et al., 2010; Clauss et al., 2013; Nichman et al., 2016). The OPC laser (Osela ILS-640-250-FTH-1.5MM$100 \mathrm{uM}$ ) is a continuous-wave $500 \mathrm{~mW} 670 \mathrm{~nm}$ laser with a top-hat beam profile. One of two sets of backscatter optics has a polarizing beam splitter and measures backscattered light in both $P$ and $S$ polarizations ( $P_{1}$ and $S_{1}$, respectively). The second set of backscatter optics only measures the $P$ polarization $\left(P_{2}\right)$. The detection angle of both sets of backscatter optics is centered at $135^{\circ}$ and has a half angle of $20^{\circ}$.

LabVIEW software is used for instrument control and data acquisition. The SPIN software program consists of several different loops and subprograms and allows for significant automation during operation. User control of the various SPIN components, including the compressors, valves, and detector is also performed and automated through the Lab-

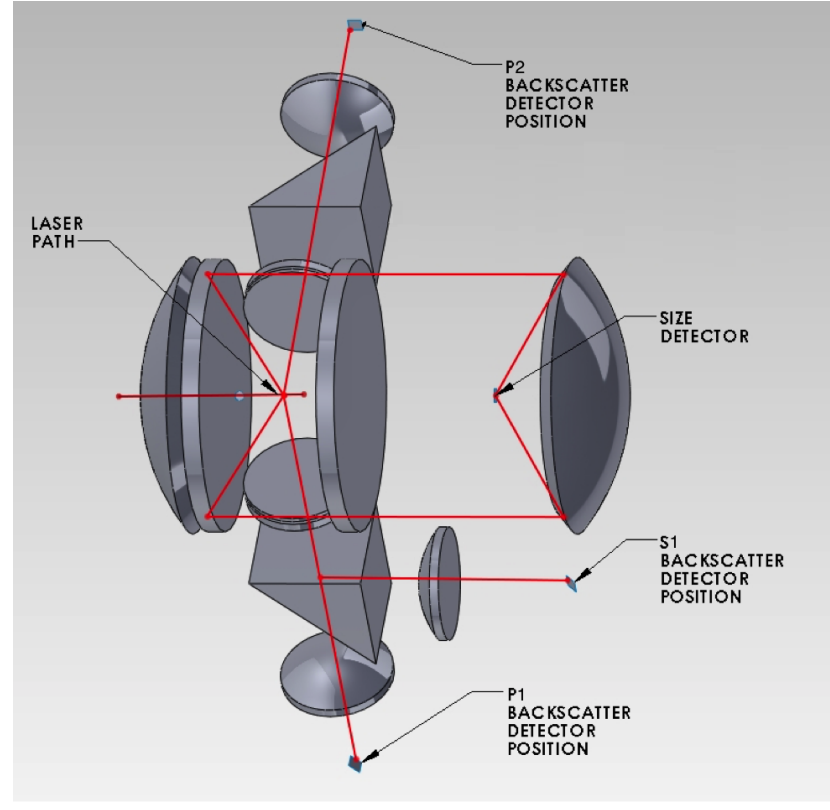

Figure 4. Schematic optical setup of the SPIN OPC. The laser light is shown entering the sampling region, with side scatter rays traveling to the sizing detector, and the backscatter rays traveling to the depolarization detectors (see Sect. 2.2 for details).

VIEW interface. Individual actions, such as toggling valves, as well as sequences, such as icing the chamber walls, are controllable through software. The software also includes functionality to create custom sequences, allowing for the majority of operations (including system and compressor startup, cooling the chamber, icing the walls, and running the activation experiments described in Sect. 3.1) to be automated for increased experimental reproducibility. High data load corresponding to large OPC concentrations will cause a drop counting efficiency: for $1 \mathrm{~L} \mathrm{~min}^{-1}$ sample flow, this corresponds to particle counts higher than $\sim 3900 \mathrm{~cm}^{-3}$, above which additional particles are not recorded. In addition to the foreground sequences initiated by the user, background sequences can also be run to monitor instrument performance. With remote access enabled through virtual network computing (VNC) software (separate from the LabVIEW software), much of the chamber operation can be performed remotely. In particular, starting the compressors, cooling the chamber, icing the chamber, switching the chamber inlet and outlet valves, and controlling chamber conditions can be performed remotely through $\mathrm{VNC}$, but refilling the water reservoir, installing/removing the OPC, and switching other valves must be performed on-site. 


\section{Methodology}

\subsection{Experimental methods}

Before beginning experiments, the chamber is dried and cooled, and the walls are coated with ice. This is accomplished by first flowing dry nitrogen through the chamber via the sample and sheath flow inlets to remove residual moisture; the flow exiting the chamber outlet is routed through a dew point sensor (Vaisala DMT152 Dewpoint Transmitter), so the moisture content of the chamber can be directly measured to ensure the dew point is below $-40^{\circ} \mathrm{C}$. The compressor system is then activated to cool the chamber (both walls of the main chamber and evaporation section) to the icing temperature of $-25^{\circ} \mathrm{C}$. Before icing, the double distilled deionized $18.2 \mathrm{M} \Omega$ Millipore (DDI) water in the reservoir is cooled to $\sim 2{ }^{\circ} \mathrm{C}$ to reduce strain on the refrigeration system during icing and to ensure that the wall temperatures do not exceed $0{ }^{\circ} \mathrm{C}$ over the course of the icing process. With the water reservoir attached to the two-way water pump, the icing sequence is activated in the software. This sequence controls the filling and emptying of the chamber with DDI water to form the ice layers. The ice dwell counter in the software specifies the amount of time the chamber is filled with water and is typically set to $5 \mathrm{~s}$. During and after the icing sequence it is critical to prevent moist room air from entering the chamber, which can cause non-uniform ice on the chamber walls via the formation of frost. This is accomplished by flowing dry air or nitrogen through the sample and sheath flow inlets while allowing the excess flow pressure to be released into the room upstream of the chamber inlets. The entire filling sequence typically lasts $\sim 5 \mathrm{~min}$. The difference in the volume of water in the reservoir before and after the icing process is used to infer the amount of ice formed, and this difference is typically $\sim 1.25 \mathrm{~L}$. After the ice layer has been formed, the dry nitrogen flow through the chamber is continued to ensure that no frost accumulates in the chamber. Subsequent installation of the detector and activation of the sheath pump allows for assessment of background frost counts that may bias the reported INP concentrations. This background concentration (typically between a few counts to several $10 \mathrm{~s}$ of counts $\mathrm{L}^{-1}$ ) influences the lower detection limit of INP.

Once the chamber is iced and has a sufficiently low background, it is ready to perform INP activation experiments. This is accomplished in one of two main ways: (1) ramping the wall temperatures to determine the temperatureand/or supersaturation-dependent ice crystal concentration or (2) keeping the walls at different but constant temperatures to measure the temporal variability of ice crystal concentration at desired temperature and supersaturation conditions. For the former, increasing the temperature gradient between the walls increases the chamber supersaturation, and decreasing the gradient decreases chamber supersaturation. Ramping both wall temperatures allows for temperature scans at the same supersaturation. For experiments in this study, the evaporation section temperature is set to be the same as the average aerosol lamina temperature. Additionally, in all cases the OPC reports side scatter (sizing) and backscatter (depolarization) spectra to infer size, concentration, and phase of counted particles.

Frost backgrounds are typically higher in the SPIN chamber at higher supersaturations, and the presence of frost in the chamber can lead to data artifacts. Therefore, periodically measuring the background frost counts with no particles in the chamber (by setting the inlet valve to the filter position for 3-5 $\mathrm{min}$ ) is an important procedure during activation experiments (described below). For converging and diverging wall temperature ramps (with typical ramp rates of $\mathrm{dRH} / \mathrm{d} t$ at $2 \% \mathrm{~min}^{-1}$ ), this check is performed at the beginning and end of each ramp. For constant supersaturation experiments, this check is performed at fixed time intervals, typically twice per hour. Experiments are automatable using sequences in the SPIN software. These sequences automate the periodic background checks as well as controlling the wall temperature set points. The background concentration increases over time as vapor is transferred from the warm wall to the cold wall, leading to irregularities in the ice layers: as a result, the experiment must be ended once it no longer meets the background levels required for the particular experiment. The exact time this occurs depends on the particular operating conditions for an experiment but is typically after $2-5 \mathrm{~h}$ of operation. For example, if a laboratory experiment with $10 \mathrm{INP} \mathrm{\textrm {cm } ^ { - 3 }}$ were to report activated fractions at the $1 \%$ level, it would require a background of no more than 100 counts $\mathrm{L}^{-1}$.

If the temperature gradient between the warm and cold walls is large (e.g., larger than $\sim 10-15^{\circ} \mathrm{C}$, depending on the actual temperatures) the buoyancy of the air adjacent to the warm wall is expected to overcome the mean flow and causes (upward) flow reversal along the warm wall (Rogers, 1988). The dashed line in the top panel of Figure 5 shows the ice saturation ratio $\left(S_{\text {ice }}\right)$ above which flow reversal is possible according to the calculations from Rogers (1988), and the bottom panels show two examples of normal and reversed flow profiles. If flow reversal interferes with the aerosol lamina, the chamber behavior may deviate from ideality (Rogers, 1988; Stetzer et al., 2008). Increasing the sheath flow combats flow reversal, but it decreases the residence time of particles in the chamber, which reduces nucleation and crystal growth efficiencies (Rogers, 1988).

\subsection{Data processing methods}

\subsubsection{Standard use}

The temperature and supersaturation conditions in the chamber are calculated, assuming a linear temperature and water vapor partial pressure gradient between the walls. The width and location of the aerosol lamina (and therefore 


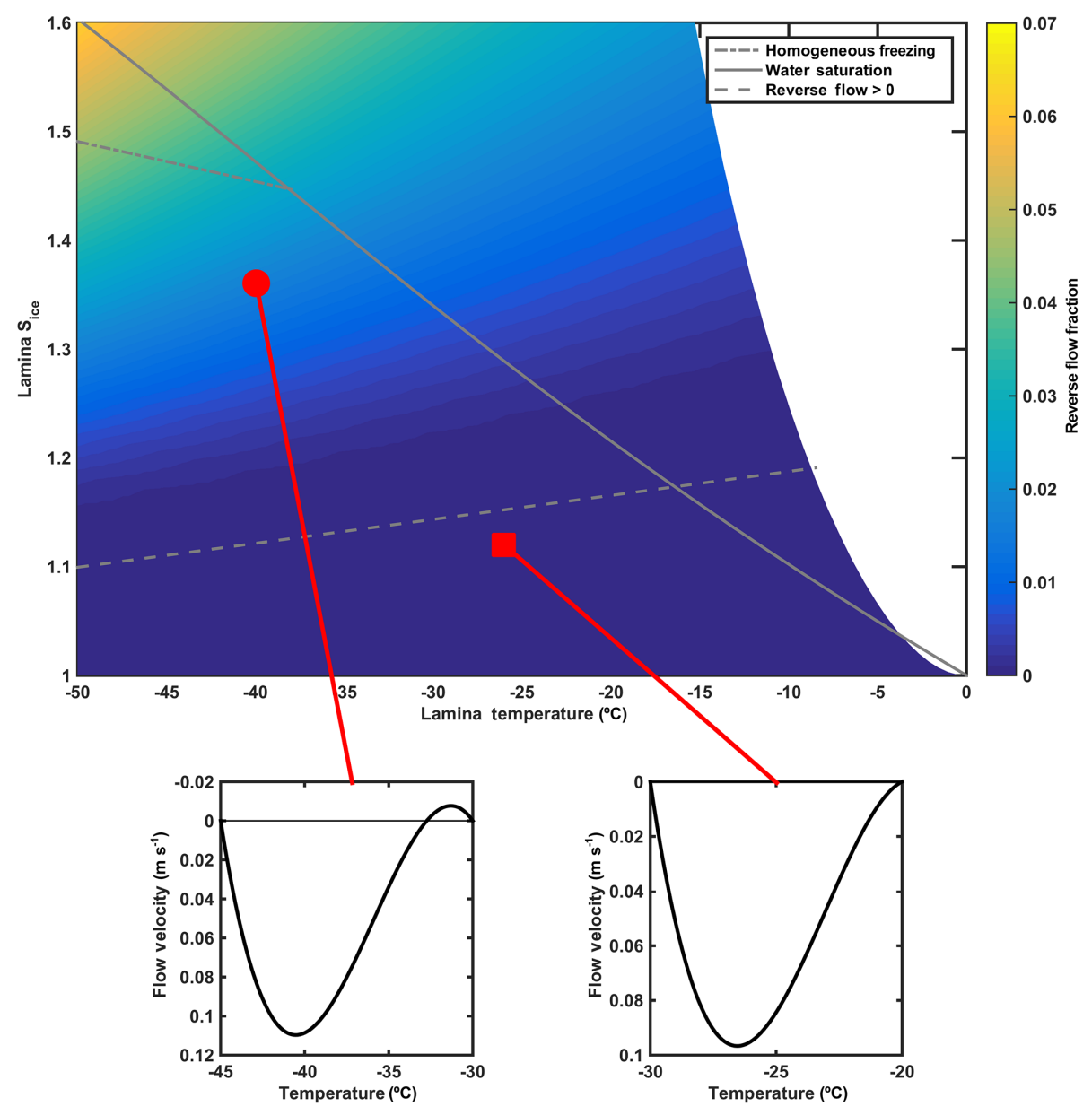

Figure 5. Phase diagram of ice saturation ratio vs. temperature showing the thermodynamic conditions accessible by CFDC chambers. The color scale shows the ratio of (upward) reverse flow to (downward) normal flow in the chamber (with $10 \mathrm{standard} \mathrm{L} \mathrm{min}^{-1}$ sheath flow, 1 standard $\mathrm{L} \mathrm{min}^{-1}$ sample flow, and $1000 \mathrm{hPa}$ chamber pressure) assuming a negligibly thick ice layer predicted by Rogers (1988) with the dashed grey line marking the boundary between zero and nonzero flow reversal (see Sect. 3.1 for details). The solid grey line is water saturation, and the grey dashed dotted line shows the onset of homogeneous freezing of solution droplets for $J=10^{11} \mathrm{~cm}^{-3} \mathrm{~s}^{-1}$ from Koop et al. (2000). Two flow profiles are shown as insets: the coldest temperature in each corresponds to the cold wall temperature and the warmest to the warm wall temperature. Flow reversal occurs along the warm wall in one case (left, red circle) and not in the other (right, red square).

the range of temperatures and supersaturations experienced by the aerosols) is calculated extending the method from Rogers (1988) using the reported values for wall temperatures (at all thermocouple locations), sheath flow rate, and sample flow rate. The thickness of the ice layer where particles nucleate is assumed to be negligible in the calculations, since the nucleation region (at the top of the chamber) has a much thinner ice layer than the chamber average. This approach provides a basis for calculating chamber conditions at each pair of thermocouples (on the warm and cold wall, respectively, at a given location). The flow rates and temperature conditions are used to calculate the velocity profile, and the ratio of the sample flow rate to the total flow rate is used to determine the width of the aerosol lamina (Rogers, 1988; Kulkarni and Kok, 2012). Since a velocity profile calcula- tion is part of this procedure, the fraction of reversed flow is known.

The above calculations provide temperatures and supersaturations as a time series along with the size distributions and depolarization signals measured by the OPC, which provides four values (one from each of the detectors) on a single particle basis. The number of aerosol particles that have activated into ice crystals or droplets in the standard use case is based on a size threshold, typically $3-5 \mu \mathrm{m}$, above which only particles that have nucleated into droplets or crystals exist. Droplet breakthrough conditions represent an upper RH limit for the standard use case because nucleated droplets and ice crystals may be indistinguishable based on size alone. Experimentally determined droplet breakthrough thresholds are presented in Sect. 4. A condensation particle counter (CPC) is typically used in parallel to SPIN to measure the concen- 

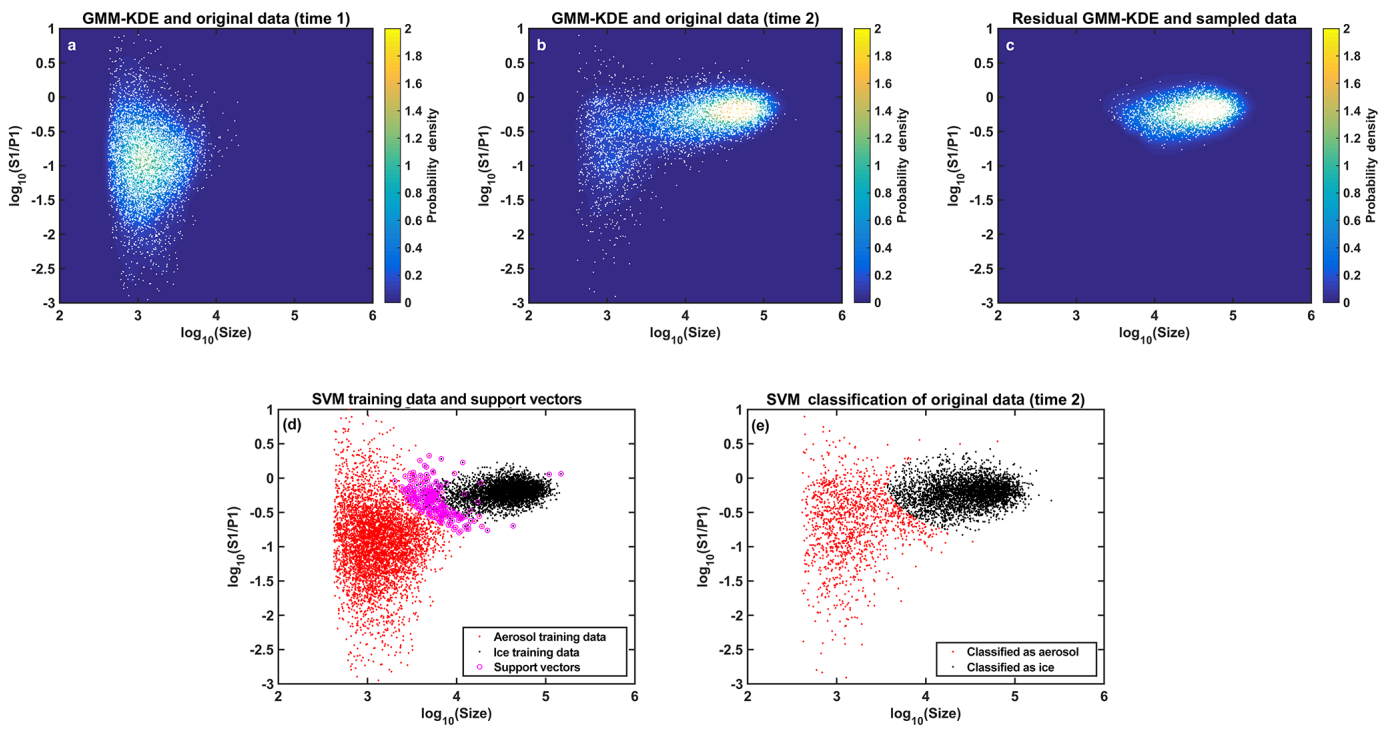

Figure 6. Illustration of the supervised ML procedure used to classify OPC data in $\log _{10}\left(S_{1} / P_{1}\right)$ vs. $\log _{10}$ (size) parameter space. The units of Size, $S_{1}$, and $P_{1}$ are all intensity counts. (a) Data and GMM-KDE for an aerosol only time interval (time 1). (b) Data and GMM-KDE for an aerosol + ice time interval (time 2). (c) Residual GMM-KDE (time 2 minus time 1) and data from weighted sampling informed by the deconvolved PDF. (d) Aerosol data, ice data, and support vectors for SVM training. Cross-validated classification accuracy is $99 \%$ in this example. (e) Data from time 2 classified by SVM as aerosol and ice. See Sect. 3.2 for details.

tration of particles entering the chamber, so the estimate of the number of ice crystals from above is used to infer activated fractions by dividing the ice crystal concentration by the total particle concentration entering the chamber.

\subsubsection{Advanced use}

In the advanced use case, the number of aerosol particles that have activated into ice crystals or droplets is inferred in post-processing from classification of the particle-by-particle $(\mathrm{PbP})$ data in the 4-D OPC parameter space via supervised machine learning (ML) (Mohri et al., 2012). This process is described below and illustrated in Fig. 6 for an example freezing experiment. Please note that the ML procedure described in this section is not an out-of-the-box functionality of the SPIN software but rather a method developed by the authors to utilize the instrument in more advanced ways.

CFDC OPC data have historically been analyzed using post-evaporation section particle size as the sole determiner of activation into ice or droplets, since ice crystals grow to be much larger than the seed particles (e.g., Rogers et al., 2001; DeMott et al., 2010; Chou et al., 2011). If particles larger than a certain size are assumed to be ice crystals, then it must either be assumed or imposed that all aerosol particles are smaller than the ice size and that droplets above that size do not survive the evaporation section. In order to meet this constraint, particle impactors are often used to prevent the largest (and potentially most ice active) particles from entering the CFDC (e.g., Rogers et al., 2001; DeMott et al., 2010, 2015). In addition, if the main chamber is supersaturated with respect to water, the aerosol particles may activate into droplets. The evaporation section is designed to avoid counting these droplets in the OPC, but it will cease to evaporate droplets completely above a threshold (temperature-dependent) supersaturation level. This droplet breakthrough threshold typically provides an upper limit for measurable supersaturation, above which droplets must be differentiated from ice crystals, and it marks the upper RH limit for traditional CFDC operation and data analysis. However, the addition of depolarization data and analysis using supervised ML algorithms allow for this size assumption to be relaxed, since all detected particles are classified by phase and the uncertainty associated with this classification is quantified (see below). In general, this ML approach provides accurate, reproducible, and uncertainty-quantifying analysis of the OPC data using preexisting MATLAB libraries (http://www.mathworks.com/help/stats/classification.html; http://www.mathworks.com/matlabcentral/fileexchange/ 41187-fast-kernel-density-estimator--multivariate-). It also requires fewer assumptions to be made about particle classification and allows more flexibility in experimental design.

Supervised ML algorithms for classification are used to assign new data to predetermined classes based on the similarity of the new data to each of these classes (Mohri et al., 2012). The different output classes in the SPIN OPC data are aerosol particles, water droplets, and ice crystals. These classes must have training data that correspond to a known class (Mohri et al., 2012). However, the SPIN OPC data from 

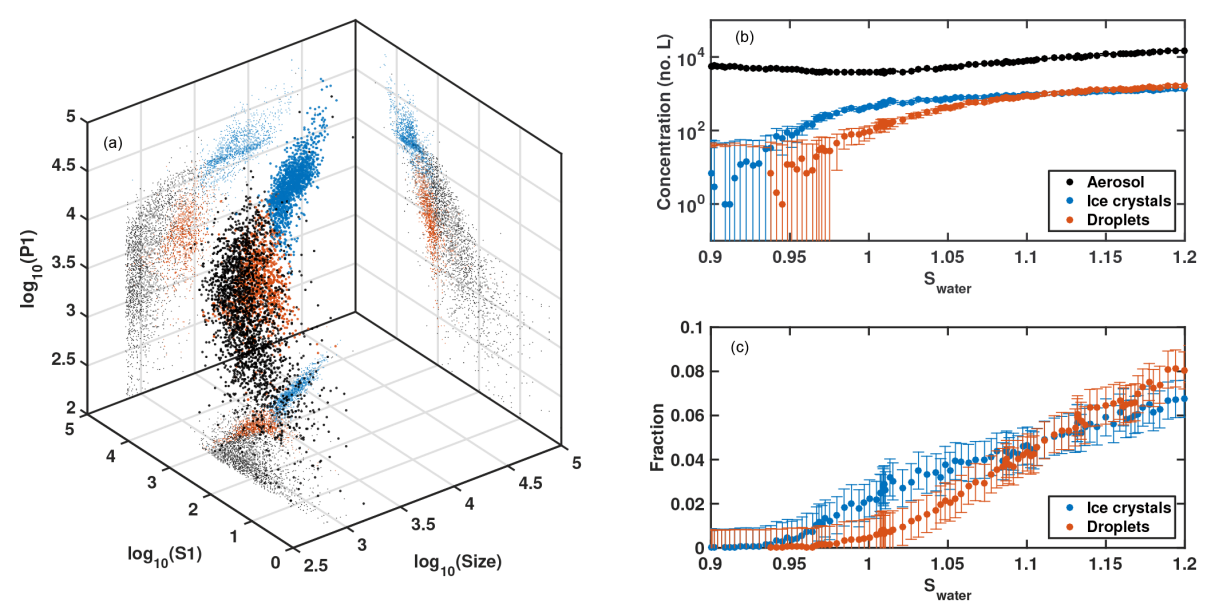

Figure 7. Application of three-class supervised ML on an example activation experiment where the chamber RH is increased. (a) Aerosol particles (black), ice crystals (blue), and water droplets (red) shown in $\log _{10}\left(P_{1}\right)$ vs. $\log _{10}\left(S_{1}\right)$ vs. $\log _{10}$ (Size) parameter space with classification accuracy of $99 \%$. 2-D projections of the data are shown at axes limits with smaller markers. (b) Concentration of aerosol particles, ice crystals, and water droplets as a function of chamber RH. Error bars represent classification uncertainty. (c) Fraction of particles activated as ice crystals and water droplets as a function of chamber RH. Error bars represent classification uncertainty. Data points with lower error bars below zero indicate that the values are statistically indistinguishable from zero.

an activation experiment typically contain mixtures of these classes rather than the pure end members, so choosing the data that correspond to a class is performed statistically. In particular, training data are sampled from a subset of the data that represents the different classes.

In order to inform this sampling, kernel density estimation (KDE) (Rosenblatt, 1956; Parzen, 1962) is used to create probability density functions (PDFs) of the data in various time intervals. Using the KDE approach to sample training data factors in the relative likelihood that a given class of particle (aerosol, droplet, or ice) will appear in an area of the parameter space. This approach takes into account the structure of the underlying PDFs of the training data to incorporate training data uncertainty into estimates of classification uncertainties.

The SPIN OPC reports four intensity count values (size, $S_{1}, P_{1}$, and $P_{2}$ ) in the $\mathrm{PbP}$ data, and KDE with automatic bandwidth estimation is used to create a 4-D Gaussian mixture model (GMM) (McLachlan and Peel, 2000) of the PDFs (one dimension corresponding to each of the intensity count values from the SPIN OPC) in this particle data following the method of Kristan et al. (2011). Figure 6 shows data from an illite NX freezing experiment at $-40{ }^{\circ} \mathrm{C}$ with ramping supersaturation. Specifically, Fig. 6a shows PbP data from the beginning of the experiment during an aerosol only time interval (time 1, when only aerosol particles are present in the chamber). It also shows the corresponding KDE: for ease of visualization the 2-D GMM-KDE in $S_{1} / P_{1}$ vs. size parameter space shown in lieu of the full 4-D GMM-KDE used in the analysis. Figure $6 \mathrm{~b}$ similarly shows data and the GMM-KDE during an aerosol + ice time interval (time 2, at a supersaturation higher than that required for the onset of ice forma- tion where both particles and ice are present). The PDF in Fig. 6a is deconvolved from the one in Fig. $6 \mathrm{~b}$ and is used to create a residual PDF, which is then used to inform the weighted sampling of data from time 2 to create training data for the ice only output class (corresponding to the region of the parameter space only ice crystals occupy, Fig. 6c). The data corresponding to the aerosol only (Fig. 6a) and ice only (Fig. 6c) classes are then used to train a supervised ML algorithm. In this example, a Gaussian kernel support vector machine (SVM) (Mohri et al., 2012) is used, and classification uncertainties are quantified via fivefold cross-validation of the training data (Fig. 6d). Once trained, the SVM classifies the OPC data from an experiment with a known missed classification percentage (Fig. 6e).

As in the standard use case, a CPC is used in parallel to SPIN to measure the concentration of particles entering the chamber, so the estimate of the number of ice crystals from above is used to infer activated fractions by again dividing the ice crystal concentration by the total particle concentration entering the chamber.

Figure 7 shows an extension of this approach to discriminate aerosol particles, water droplets and ice crystals using an application of three-class supervised ML (Mohri et al., 2012). Bootstrap aggregated decision trees (Breiman, 1996) are used for the classification instead of SVM in this case because this classification algorithm outperforms SVM in terms of classification error in the three-class case; both algorithms are operationally interchangeable, so the better performing one with respect to classification error was chosen. This example shows a (dry-generated, polydisperse) silver iodide (AgI) activation experiment at $-17^{\circ} \mathrm{C}$ where the chamber $\mathrm{RH}$ is increased. Though a 4-D parameter space is again 
used for this classification, Fig. 7a shows only three of the $\mathrm{PbP}$ data dimensions along with 2-D projections at the axes limits to illustrate the portions of the parameter space occupied by each class. With this approach, the concentrations (Fig. 7b) and fractions (Fig. 7c) of ice crystals and water droplets along with classification uncertainty are reported as a function of chamber conditions (note that evaporation section reduces droplet fractions, even above the droplet breakthrough point). The time series data are corrected for background frost by quantifying the frost counts that are classified as ice crystals by the algorithm. At the subsaturated RH conditions in Fig. 7c, data with lower error bars that are not greater than zero show activated fractions that are statistically indistinguishable from zero. Overall, with the large datasets (up to thousands of data points per second) generated by the SPIN OPC, particle classification is performed in a reproducible manner with classification accuracies of 95.0$99.9 \%$

Once similarly large datasets are generated for field measurements in future studies, ML classifiers can be used for distinguishing frost from real ice in the field. The general ML approach can also be used for other instruments with sizeonly data; for example, an SVM that uses size only would find the optimal size (by maximizing the margin between ice and aerosol training data) to distinguish the two classes and quantify the uncertainty associated with choosing this size via cross-validation.

\section{Results and comparisons to literature}

To evaluate the performance of the SPIN OPC, sizing and detection experiments are performed with different sizes of monodisperse spheres. Glass beads, polystyrene latex spheres, and melamine resin spheres are used for the characterizations. The results from these calibrations are shown in Fig. 8, and illustrate how the SPIN OPC sizes particles (Fig. 8a). The sizing behavior follows a power law fit for particle sizing between 0.5 and $11 \mu \mathrm{m}$. Smaller particles scatter the laser light less efficiently, and rapidly decreasing detection efficiency with decreasing size is observed for submicrometer particles (Fig. 8b). In the super-micrometer size range (where ice crystals are expected to be present) the counting efficiency is very close to 1 .

To evaluate the behavior of the SPIN chamber, several types of freezing experiments are reported. Specifically, $200 \mathrm{~nm}$ (nebulized, dried, and mobility selected) ammonium sulfate (AS) aerosol is used to determine the droplet breakthrough line and to compare the deliquesced haze droplet homogeneous freezing points reported by SPIN to literature values. In addition, polydisperse, dry-generated NX illite and AgI (Sigma Aldrich $>99 \%$, with a narrow mobility size distribution between 200 and $300 \mathrm{~nm}$ ) particles are used to investigate the heterogeneous ice activation for comparison to literature (note that the purity levels of AgI in previous stud-
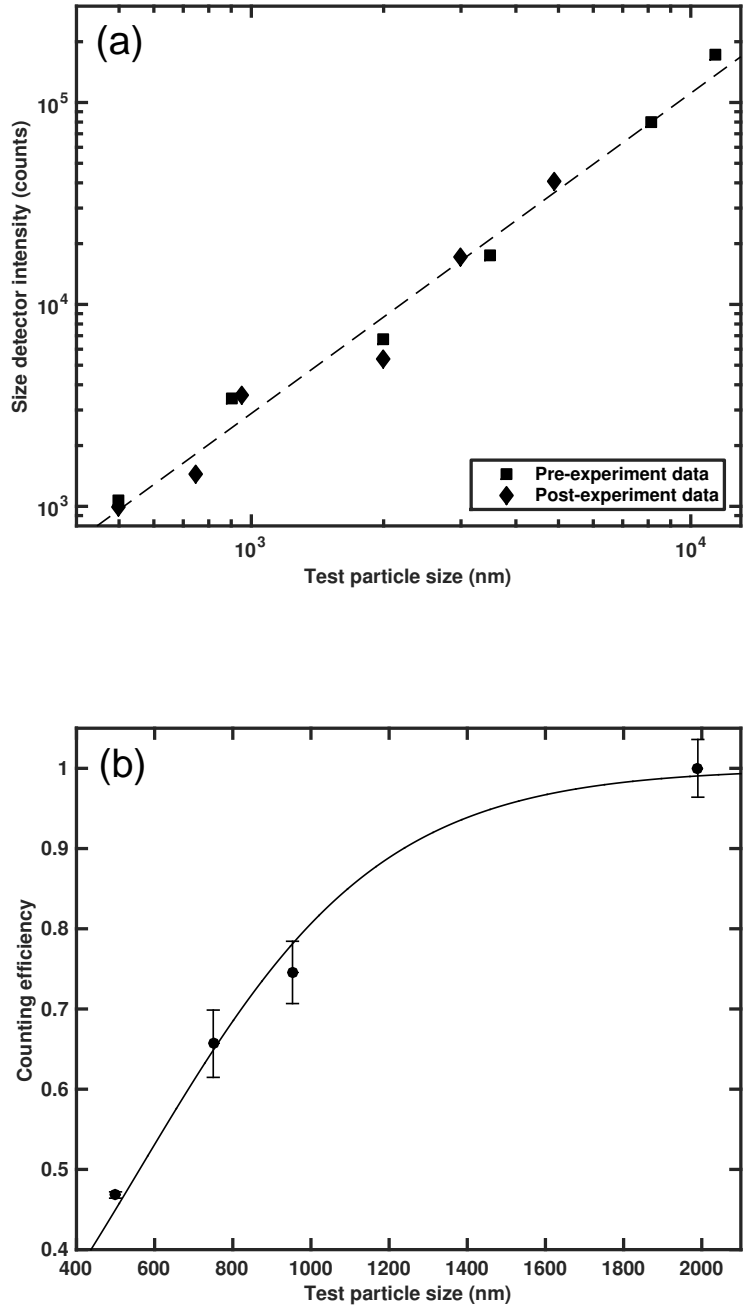

Figure 8. Particle sizing and transmission efficiency of the SPIN detector. (a) Detector intensity counts vs. test particle size before and after the freezing experiments in this study. The dashed line shows the power law fit to the data. (b) Size-dependent counting efficiency of AS particles with sigmoid fit. Error bars show measurement uncertainty.

ies is unknown). The homogeneous freezing results shown in Fig. 9 suggest that the temperatures and supersaturations reported by SPIN are indicative of the real conditions in the chamber. Similarly, the results from the heterogeneous freezing experiments are shown in Fig. 10 and indicate that freezing occurs in the expected regions of phase space for the different seed particles.

AS data are used to characterize SPIN's behavior in humid (near or above water saturation) conditions across a wide range of temperatures. AS freezing experiments at colder temperatures compare the chamber performance to the wellcharacterized homogeneous freezing behavior of deliquesced haze droplets. Though solid AS has been observed to nucleate in the deposition mode (Abbatt et al., 2006), this effect is negligible for the temperatures and activated fractions con- 


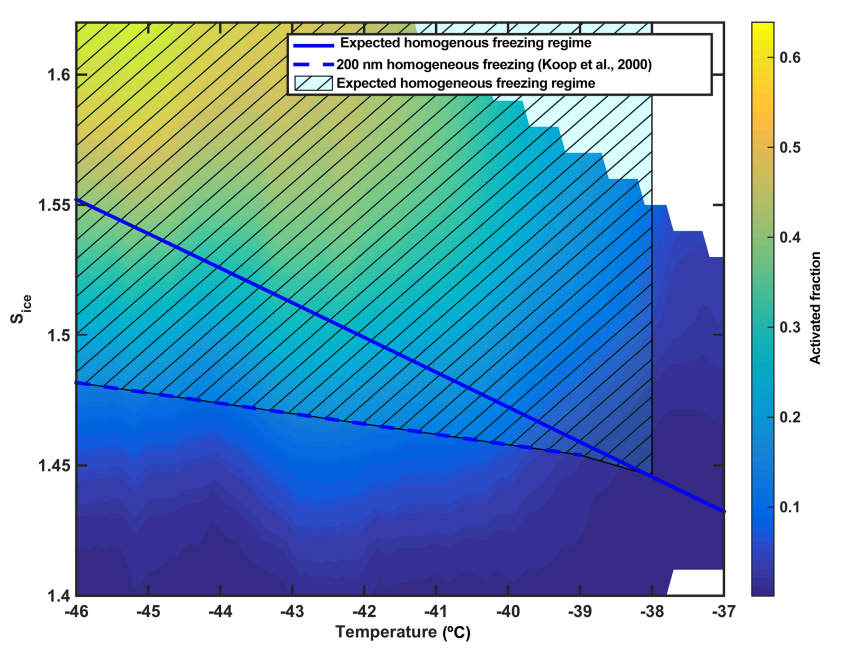

Figure 9. Experimental homogeneous freezing results. The hatched and shaded area shows where homogeneous freezing of deliquesced haze droplets is expected to occur (below $-38^{\circ} \mathrm{C}$ and above the $J=10^{11} \mathrm{~cm}^{-3} \mathrm{~s}^{-1}$ line from Koop et al., 2000). The color contours show interpolated activated fraction of ice crystals as a function of chamber conditions from 38 experiments (white areas are where no data are present). Typical aerosol number concentrations for such experiments are $100 \mathrm{~s}$ of particles $\mathrm{cm}^{-3}$. Typical uncertainties at 1 standard deviation for temperature are $\pm 1{ }^{\circ} \mathrm{C}$, for supersaturation are $\pm 5 \%$, and for activated fraction are $<1 \%$.

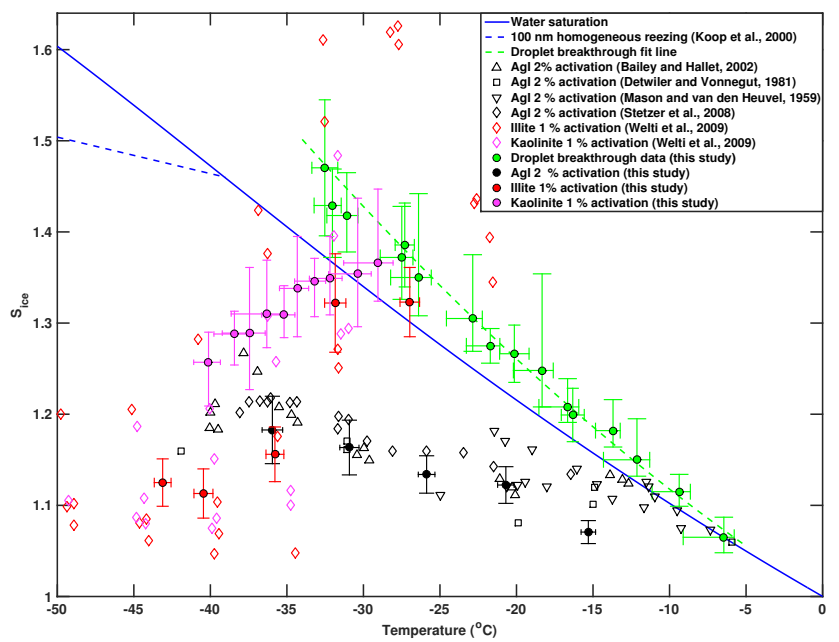

Figure 10. Experimental heterogeneous ice nucleation results and comparison to literature with polydisperse NX illite, AgI, and $500 \mathrm{~nm}$ kaolinite particles. AS droplet breakthrough data and corresponding (quadratic) fit line are shown in green. Error bars represent uncertainty in lamina temperature and supersaturation conditions. The homogenous freezing line for solution droplets for $J=10^{11} \mathrm{~cm}^{-3} \mathrm{~s}^{-1}$ from Koop et al. (2000) is also shown for reference.

sidered in this study. The data in Fig. 9 show that this behavior is captured in both temperature and $\mathrm{RH}$ ramps and occurs in the expected region of phase space. They demon- strate that droplets in SPIN begin to freeze when the chamber temperature falls below $\sim-38^{\circ} \mathrm{C}$ and that homogeneously frozen ice crystals begin to disappear above this temperature. Similarly, the RH ramp data show that supercooled aqueous AS haze droplets freeze at RH levels similar to those predicted by the Koop et al. (2000) line for a homogeneous nucleation rate coefficient $J=10^{11} \mathrm{~cm}^{-3} \mathrm{~s}^{-1}$. The effects of multiply charged particles are also negligible because the uncertainty contributed by these particles on expected homogenous freezing supersaturation $( \pm \sim 1 \% \mathrm{RH}$ using the relevant values from Koop et al., 2000) is smaller than the other measurement uncertainties of these experiments $( \pm \sim 5 \%$ $\mathrm{RH})$.

At warmer temperatures, homogeneous freezing does not occur, so AS is used to measure SPIN's droplet breakthrough threshold. Though post-processing of the $\mathrm{PbP}$ detector data can distinguish droplets from ice (Sect. 3.2), droplet breakthrough is quantified using AS (which is much more hygroscopic than many INPs) and provides a conservative (lower $\mathrm{RH}$ ) estimate for where this occurs. The measured droplet breakthrough line indicates that SPIN's evaporation section extends (a few percent above water saturation) the region of phase space where experiments can be performed without needing to differentiate droplets from ice crystals.

AgI, despite not being found in the atmosphere, nucleates very efficiently in the deposition mode across a range of temperatures and provides a benchmark to assess chamber performance (e.g., Detwiler and Vonnegut, 1981; Stetzer et al., 2008). The SPIN results shown in Fig. 10 match literature data across a wide temperature range and demonstrate that SPIN accurately captures ice nucleation at warmer temperatures where there are many atmospherically relevant INPs that activate into ice crystals. In addition to AgI results, heterogeneous freezing results for NX illite and kaolinite are also included, because they are commonly used surrogates for atmospheric dust, which is important for ice nucleation at colder temperatures (DeMott et al., 2003b; Welti et al., 2009; Cziczo et al., 2013). Unlike AgI, NX illite and kaolinite show a strong temperature dependence in freezing behavior and nucleate ice much less efficiently at temperatures warmer than $\sim-35^{\circ} \mathrm{C}$. Previous investigation of these materials has shown this transition (e.g., Welti et al., 2009), and the SPIN data in this study also capture this temperature dependence. Additionally, the coldest illite data points demonstrate that SPIN can access temperatures in the cirrus cloud regime.

Figure 11 shows SPIN performance during an exemplary ambient measurement taken in Cambridge, MA, on 14 April 2016 with an aerosol temperature of $\sim-30^{\circ} \mathrm{C}$ and water saturation ratio $\left(S_{\text {liq }}\right)$ of 1.05 (reported lamina temperature was $-30.7^{\circ} \mathrm{C} \pm 0.2^{\circ} \mathrm{C}$ and lamina $S_{\text {liq }}$ was $1.05 \pm 0.01$ over the measurement period). Polydisperse ambient aerosol was sampled through an inline molecular sieve dryer with no upstream impaction. The SPIN sheath flow was provided from a dry nitrogen cylinder (instead of recirculating flow 

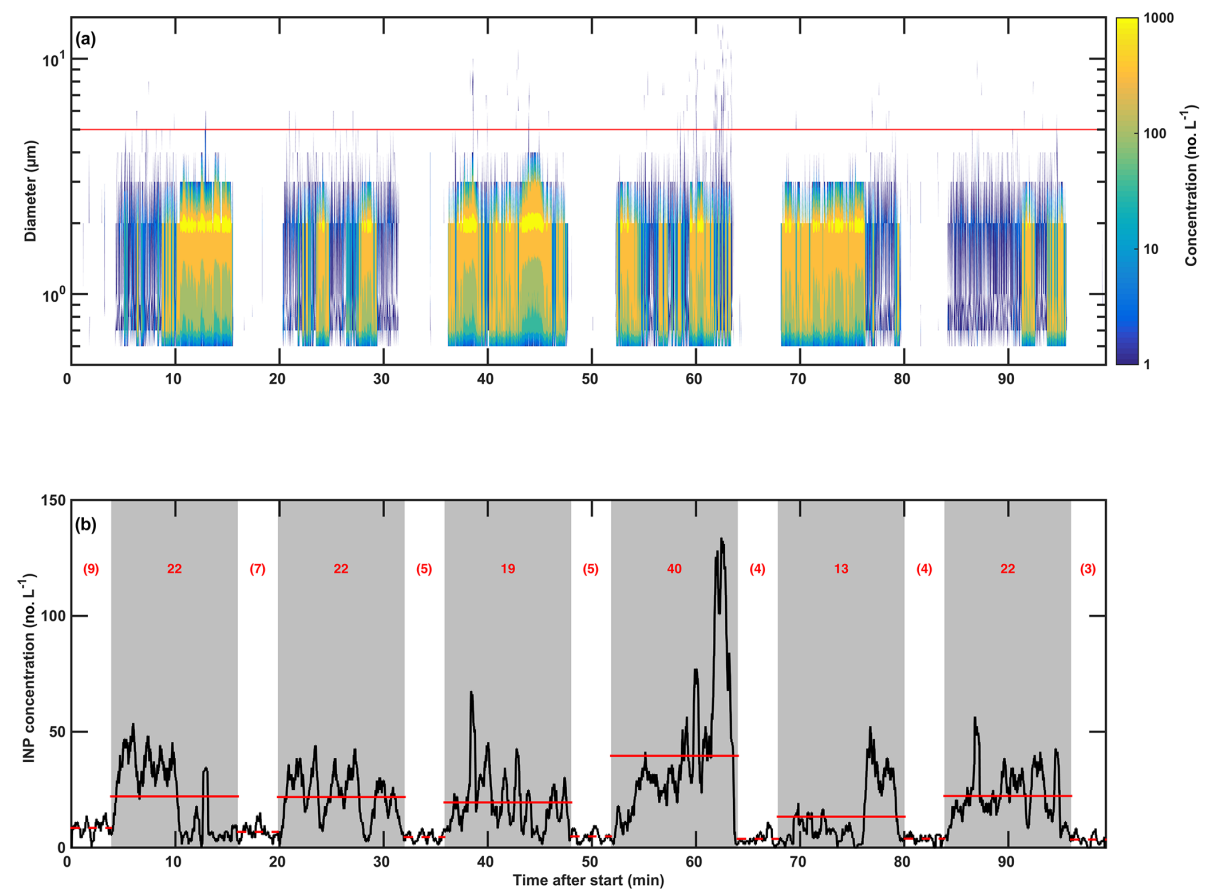

Figure 11. Example field measurement at $\sim-30^{\circ} \mathrm{C}$ and $S_{\text {liq }}=1.05$ (reported lamina temperature of $-30.7^{\circ} \mathrm{C} \pm 0.2^{\circ} \mathrm{C}$ and lamina $S_{\text {liq }}$ of $1.05 \pm 0.01$ over the measurement period). (a) The OPC size histogram time series for this measurement. The red horizontal line shows the $5 \mu \mathrm{m}$ size threshold for ice. (b) INP concentration time series using the $5 \mu \mathrm{m}$ size threshold. Shaded areas show measurement periods and unshaded areas show filter periods. Solid red horizontal lines show average INP concentrations from measurement periods (with the value specified above). Dashed red horizontal lines show average frost concentrations during filter periods (with the value specified above in parentheses).

through a dryer) to minimize frost. Assuming a $5 \mu \mathrm{m}$ threshold for ice yields $13-40 \mathrm{INP} \mathrm{L}^{-1}$ in the measurement periods and 3-9 frost counts $\mathrm{L}^{-1}$ during the filter periods; the INP concentration adjusted for frost was then $9-36 \mathrm{INPL}^{-1}$ over the entire measurement period.

\section{Measurement uncertainty}

With a CFDC instrument, there are various sources of uncertainty that influence experimental results (e.g., Rogers, 1988; Stetezer et al., 2008). Uncertainties in wall temperatures, flows, numbers of counted ice crystals, flow reversal, and other deviations from ideality must be considered when interpreting results from a CFDC chamber. In SPIN, wall temperatures are recorded at 16 locations on each wall. The aerosol lamina temperature and supersaturation conditions are calculated based on the measurements at these locations, providing a way to infer the variations in thermodynamic conditions experienced by the aerosol. Since the three bottommost thermocouples are strongly coupled to the evaporation section and occupy the transition region between the moist main chamber and dry evaporation section, only the top 13 thermocouples are used for reporting average chamber conditions. Therefore, uncertainty in chamber conditions is reported as the standard deviation of the lamina tempera- ture and RH at these 13 locations. Variability in the wall temperatures depends on operating conditions (but typically has a standard deviation of $0.5-2{ }^{\circ} \mathrm{C}$ ), and these variations must be included in uncertainty estimates. Along with these temperature gradients, variations in temperature and supersaturation across the width of the aerosol lamina are sources of uncertainty in SPIN measurements. The width of the aerosol lamina itself can be a source of uncertainty (Garimella et al., 2015), and merits investigation in future work. For the purposes of this study, misclassification error from the ML approach is used for reporting uncertainties in ice crystal concentrations and activated fractions.

Computational fluid dynamics (CFD) calculations in this section are used to explore how closely simulated chamber conditions match ideality. Figure 12 shows results from ANSYS Fluent CFD modeling (Fluent, 2015) of the SPIN chamber. Several simulations were performed and results from two of these are shown. Specifically, the left column in Fig. 12 shows results for nominal lamina temperature of $-40^{\circ} \mathrm{C}$ and lamina $S_{\text {ice }}$ at 1.3 , and the right column shows results for nominal lamina temperature of $-30^{\circ} \mathrm{C}$ and lamina $S_{\text {ice }}$ at 1.1. Overall, simulated chamber temperature, $\mathrm{RH}$, and flow velocity match the ideal case predicted by Rogers (1988) for these and other Fluent experiments. Flow reversal along the warm wall (Fig. 5) is also observed in high RH simula- 


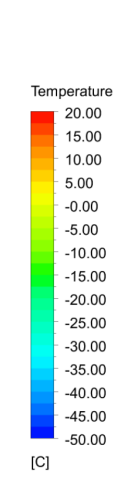

(a)

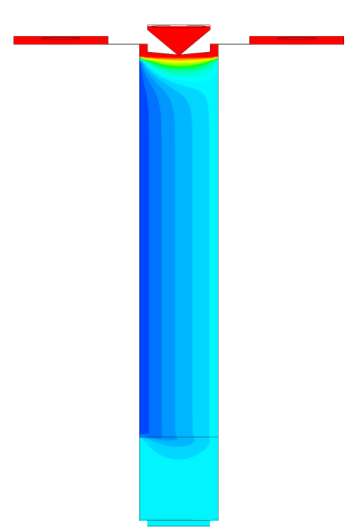

\begin{tabular}{|l} 
\\
Water Sr Wrt Ice \\
1.40 \\
1.30 \\
1.20 \\
1.10 \\
1.00 \\
0.90 \\
0.80 \\
0.70 \\
0.60 \\
0.50 \\
0.40 \\
0.30 \\
0.20 \\
0.10 \\
0.00
\end{tabular}

(c)

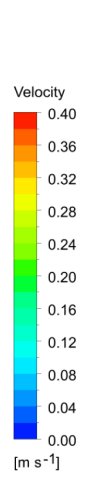

(e)
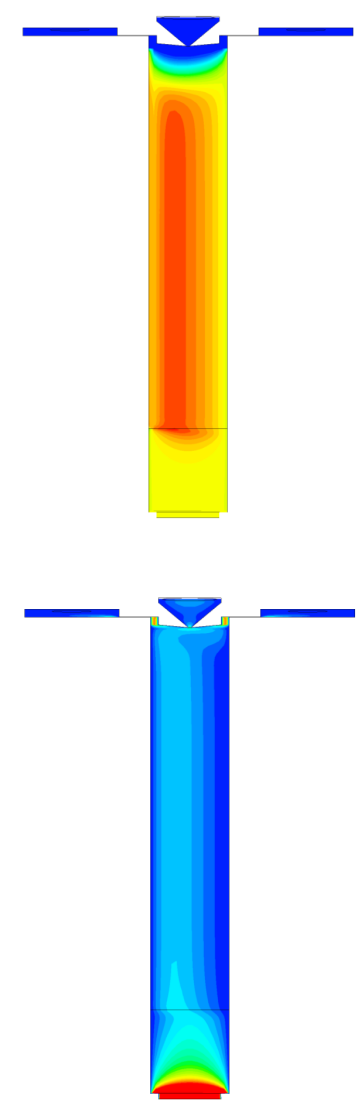

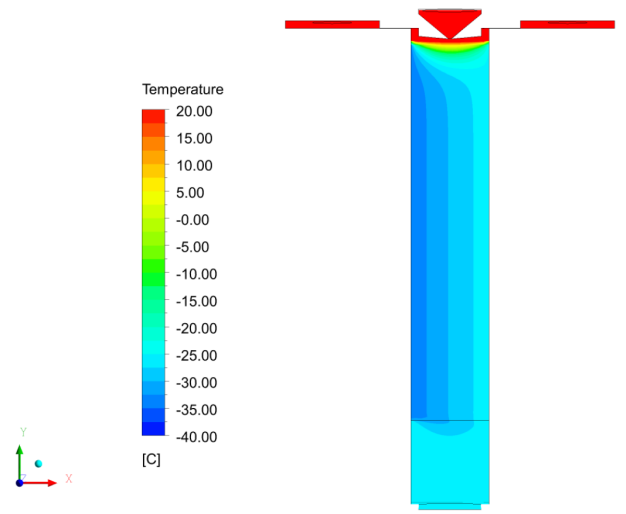

(b)

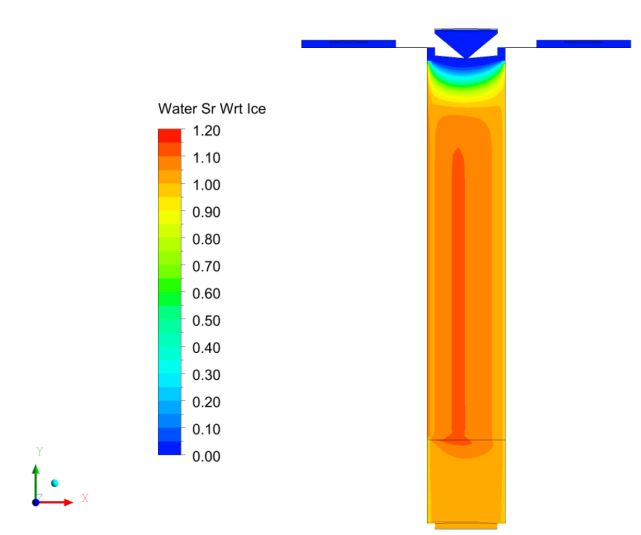

(d)

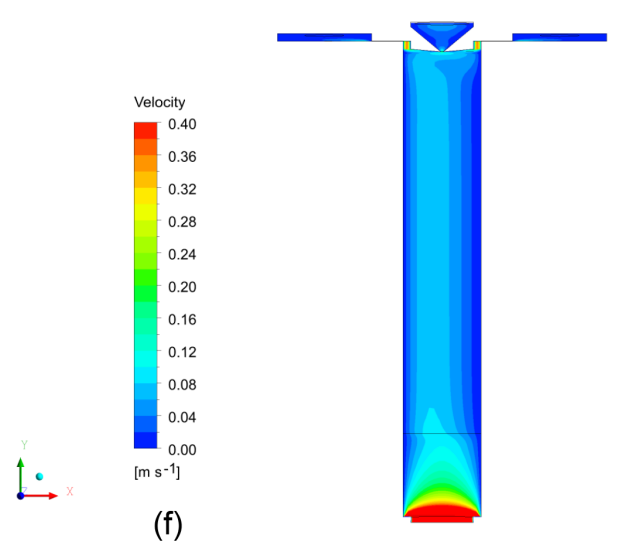

Figure 12. Fluent simulation results for two sets of chamber conditions in a cross-sectional view. The left column shows results for nominal lamina temperature of $-40{ }^{\circ} \mathrm{C}$ and lamina $S_{\text {ice }}$ at 1.3 . (a) Temperature $\left({ }^{\circ} \mathrm{C}\right)$, (c) $\mathrm{S}_{\text {ice, }}$, and (e) flow velocity ( $\mathrm{m} \mathrm{s}^{-1}$ ). The right column shows results for nominal lamina temperature of $-30^{\circ} \mathrm{C}$ and lamina $S_{\text {ice }}$ at 1.1 . (b) Temperature $\left({ }^{\circ} \mathrm{C}\right),(\mathbf{d}) S_{\text {ice }}$, and (f) flow velocity $\left(\mathrm{m} \mathrm{s}^{-1}\right)$.

tions, but as with the physical experiments, this effect does not appear to have an appreciable influence on the aerosol lamina conditions beyond that which is predicted by the Rogers (1988) model. Since the analytical and CFD models show qualitatively similar flow reversal, this effect is accounted for when reporting chamber conditions with the analytical model. Furthermore, agreement between the homogeneous freezing data and expected homogeneous freez- ing conditions provides evidence, similar to that shown by Richardson (2009), that this effect does not bias results since these experiments are performed where the largest degree of flow reversal is expected. 


\section{Conclusions}

This study outlines the operating principles, chamber design, and experimental results from the SPIN chamber, a commercially available CFDC chamber manufactured by DMT. The results from this study evaluate the SPIN chamber performance using a variety of experimental tests and CFD modeling.

The introduction of SPIN as a commercially available ice chamber is similar to the introduction of the DMT Cloud Condensation Nuclei Counter (Roberts and Nenes, 2005; Lance et al., 2006), potentially allowing these measurements to be made with higher temporal and spatial coverage. In addition, the methodologies highlighted in this study facilitate the performance of INP measurements with increased experimental flexibility and reproducibility and also with fewer assumptions in the analysis. In particular, the addition of a depolarization detector coupled with supervised ML algorithms for data analysis allows for robust determination of the particle phase with uncertainty quantification. These results motivate future work to extend the ML approach to field data analysis and to intercompare the SPIN chamber performance with other INP counters in the laboratory and in the field.

The experiments presented in this study illustrate SPIN's measurements of freezing behavior of both the heterogeneous and homogeneous regimes and demonstrate that the SPIN chamber reproduces freezing data measured in previous studies. The AgI measurements span a wide range of temperatures, extending to regions where the more efficient atmospheric INPs would activate into crystals. The NX illite and kaolinite measurements demonstrate that SPIN measures into the heterogeneous freezing portion of the cirrus cloud regime and also captures the temperature dependence of mineral dust ice activity. The AS experiments provide an estimate of the droplet breakthrough level of the SPIN chamber at warmer temperatures, and at colder temperatures shows that homogeneous freezing of deliquesced haze droplets occurs in agreement with previous experiments and theory. By using an uncertainty quantifying OPC analysis technique, recording high spatial resolution temperature measurements along the chamber walls, and investigating the chamber conditions using CFD modeling, the main sources of uncertainty in SPIN measurements have also been studied.

Overall, the SPIN chamber reproduces laboratory data measured by previous CFDC chambers, and the uncertainties in the measurements have been investigated. The commercial availability of such an instrument may allow for increased coverage of INP measurements that will help constrain the influence of ice nucleation on the atmospheric radiation budget and the initiation of precipitation, thereby leading to a better understanding of the impact of ice formation on the Earth's climate and water budget.

\section{Data availability}

Data used to generate the results figures are included in a Harvard Dataverse dataset with the same name as this paper (Garimella, 2016, doi:10.7910/DVN/V28O4P).

Acknowledgements. The development of the SPIN instrument was supported by the US Department of Energy, Office of Science, STTR program, under award number DE-SC-0004258. S. Garimella and D. J. Cziczo would like to acknowledge NASA grant NNX13AO15G and the MIT Martin Family Society for Sustainability for funding. T. B. Kristensen and F. Stratmann gratefully acknowledge funding from the German Federal Ministry of Education and Research (BMBF) through the CLOUD-12 project (01LK1222B). K. Ignatius and L. Nichman gratefully acknowledge funding from the EC Seventh Framework Programme (Marie Curie Initial Training Networks MC-ITN CLOUD-TRAIN grant no. 316662). T. W. Wilson acknowledges funding from the Natural Environment Research Council (NE/K004417/1). The authors also thank Paul DeMott and other reviewers for the useful comments that have significantly improved the manuscript.

Edited by: S. Malinowski

\section{References}

Abbatt, J. P. D., Benz, S., Cziczo, D. J., Kanji, Z., Lohmann, U., and Möhler, O.: Solid Ammonium Sulfate Aerosols as Ice Nuclei: A Pathway for Cirrus Cloud Formation, Science, 313, 1770-1773, doi:10.1126/science.1129726, 2006.

Boucher, O., Randall, D., Artaxo, P., Bretherton, C., Feingold, G. Forster, P., Kerminen, V.-M., Kondo, Y., Liao, H., Lohmann, U., Rasch, P., Satheesh, S., Sherwood, S., Stevens, B., and Zhang, X.: Clouds and aerosols, in: Climate Change 2013: The Physical Science Basis, Working Group I Contribution to the Fifth Assessment Report of the Intergovernmental Panel on Climate Change, Cambridge, United Kingdom and New York, NY, USA, 571-657, 2013.

Breiman, L.: Bagging Predictors, Mach. Learn., 24, 123-140, doi:10.1007/BF00058655, 1996.

Chen, Y. L., Kreidenweis, S. M., McInnes, L. M., Rogers, D. C., and DeMott, P. J.: Single particle analyses of ice nucleating aerosols in the upper troposphere and lower stratosphere, Geophys. Res. Lett., 25, 1391-1394, doi:10.1029/97gl03261, 1998.

Chou, C., Stetzer, O., Weingartner, E., Jurányi, Z., Kanji, Z. A., and Lohmann, U.: Ice nuclei properties within a Saharan dust event at the Jungfraujoch in the Swiss Alps, Atmos. Chem. Phys., 11, 4725-4738, doi:10.5194/acp-11-4725-2011, 2011.

Chou, C., Kanji, Z. A., Stetzer, O., Tritscher, T., Chirico, R., Heringa, M. F., Weingartner, E., Prévôt, A. S. H., Baltensperger, U., and Lohmann, U.: Effect of photochemical ageing on the ice nucleation properties of diesel and wood burning particles, Atmos. Chem. Phys., 13, 761-772, doi:10.5194/acp-13-761-2013, 2013.

Clauss, T., Kiselev, A., Hartmann, S., Augustin, S., Pfeifer, S., Niedermeier, D., Wex, H., and Stratmann, F.: Application of linear polarized light for the discrimination of frozen and liquid 
droplets in ice nucleation experiments, Atmos. Meas. Tech., 6, 1041-1052, doi:10.5194/amt-6-1041-2013, 2013.

Cziczo, D. J., Froyd, K. D., Hoose, C., Jensen, E. J., Diao, M., Zondlo, M. A., Smith, J. B., Twohy, C. H., and Murphy, D. M.: Clarifying the dominant sources and mechanisms of cirrus cloud formation, Science, 340, 1320-1324, doi:10.1126/science.1234145, 2013.

DeMott, P. J., Cziczo, D. J., Prenni, A. J., Murphy, D. M., Kreidenweis, S. M., Thomson, D. S., Borys, R., and Rogers, D. C.: Measurements of the concentration and composition of nuclei for cirrus formation, P. Natl. Acad. Sci. USA, 100, 14655-14660, doi:10.1073/pnas.2532677100, 2003a.

DeMott, P. J., Sassen, K., Poellot, M. R., Baumgardner, D., Rogers, D. C., Brooks, S. D., Prenni, A. J., and Kreidenweis, S. M.: African dust aerosols as atmospheric ice nuclei, Geophys. Res. Lett., 30, 1732, doi:10.1029/2003gl017410, 2003b.

DeMott, P. J., Prenni, A. J., Liu, X., Petters, M. D., Twohy, C. H., Richardson, M. S., Eidhammer, T., Kreidenweis, S. M., and Rogers, D. C.: Predicting global atmospheric ice nuclei distributions and their impacts on climate, P. Natl. Acad. Sci. USA, 107, 11217-11222, doi:10.1073/pnas.0910818107, 2010.

DeMott, P. J., Prenni, A. J., McMeeking, G. R., Sullivan, R. C., Petters, M. D., Tobo, Y., Niemand, M., Möhler, O., Snider, J. R., Wang, Z., and Kreidenweis, S. M.: Integrating laboratory and field data to quantify the immersion freezing ice nucleation activity of mineral dust particles, Atmos. Chem. Phys., 15, 393-409, doi:10.5194/acp-15-393-2015, 2015.

Detwiler, A. G. and Vonnegut, B.: Humidity required for ice nucleation from the vapor onto silver iodide and lead iodide aerosols over the temperature range -6 to $-67^{\circ} \mathrm{C}$, J. Appl. Meteorol., 20, 1006-1012, doi:10.1175/15200450(1981)020<1006:HRFINF>2.0.CO;2, 1981.

Fluent 16.0 User's Guide, ANSYS Inc., Cecil Township, PA, USA, 2015.

Friedman, B., Zelenyuk, A., Beranek, J., Kulkarni, G., Pekour, M., Gannet Hallar, A., McCubbin, I. B., Thornton, J. A., and Cziczo, D. J.: Aerosol measurements at a high-elevation site: composition, size, and cloud condensation nuclei activity, Atmos. Chem. Phys., 13, 11839-11851, doi:10.5194/acp-13-11839-2013, 2013.

Garimella, S.: The SPectrometer for Ice Nuclei (SPIN): an instrument to investigate ice nucleation, Harvard Dataverse, V1, doi:10.7910/DVN/V28O4P, 2016.

Garimella, S., Voigtländer, J., Kulkarni, G., Stratmann, F., and Cziczo, D. J.: Biases in field measurements of ice nuclei concentrations, AGU Fall Meeting, 2015.

Gettelman, A., Liu, X., Barahona, D., Lohmann, U., and Chen, C. C.: Climate Impacts of Ice Nucleation, J. Geophys. Res., 117, D20201, doi:10.1029/2012JD017950, 2012.

Hoose, C. and Möhler, O.: Heterogeneous ice nucleation on atmospheric aerosols: a review of results from laboratory experiments, Atmos. Chem. Phys., 12, 9817-9854, doi:10.5194/acp-12-98172012, 2012.

Jones, H. M., Flynn, M. J., DeMott, P. J., and Möhler, O.: Manchester Ice Nucleus Counter (MINC) measurements from the 2007 International workshop on Comparing Ice nucleation Measuring Systems (ICIS-2007), Atmos. Chem. Phys., 11, 53-65, doi:10.5194/acp-11-53-2011, 2011.

Kanji, Z. A. and Abbatt, J. P. D.: The University of Toronto Continuous Flow Diffusion Chamber (UT-CFDC): A Simple De- sign for Ice Nucleation Studies, Aerosol Sci. Tech., 43, 730-738, doi:10.1080/02786820902889861, 2009.

Kanji, Z. A., Welti, A., Chou, C., Stetzer, O., and Lohmann, U.: Laboratory studies of immersion and deposition mode ice nucleation of ozone aged mineral dust particles, Atmos. Chem. Phys., 13, 9097-9118, doi:10.5194/acp-13-9097-2013, 2013.

Koop, T., Luo, B. P., Tsias, A., and Peter, T.: Water activity as the determinant for homogeneous ice nucleation in aqueous solutions, Nature, 406, 611-614, doi:10.1038/35020537, 2000.

Kristan, M., Leonardis, A., and Skocaj, D.: Multivariate online kernel density estimation with Gaussian kernels, Pattern Recogn., 44, 2630-2642, doi:10.1016/j.patcog.2011.03.019, 2011.

Kulkarni, G. and Kok, G.: Mobile Ice Nucleus Spectrometer, Pacific Northwest National Laboratory, Richland, WA, 2012.

Kulkarni, G., Dobbie, S., and McQuaid, J. B.: A new thermal gradient ice nucleation diffusion chamber instrument: design, development and first results using Saharan mineral dust, Atmos. Meas. Tech., 2, 221-229, doi:10.5194/amt-2-221-2009, 2009.

Lance, S., Medina, J., Smith, J. N., and Nenes, A.: Mapping the operation of the DMT Continuous Flow CCN counter, Aerosol Sci Tech., 40, 242-254, doi:10.1080/02786820500543290, 2006.

Liou, K. N. and Lahore, H.: Laser Sensing of Cloud Composition - Backscattered Depolarization Technique, J. Appl. Meteorol., 13, 257-263, doi:10.1175/15200450(1974)013<0257:1socca>2.0.co;2, 1974.

McLachlan, G. and Peel, D.: Finite mixture models, Wiley, New York, 2000.

Mohri, M., Rostamizadeh, A., and Talwalkar, A.: Foundations of Machine Learning, MIT Press, Cambridge, MA, USA, 2012.

Nichman, L., Fuchs, C., Järvinen, E., Ignatius, K., Höppel, N. F., Dias, A., Heinritzi, M., Simon, M., Tröstl, J., Wagner, A. C., Wagner, R., Williamson, C., Yan, C., Connolly, P. J., Dorsey, J. R., Duplissy, J., Ehrhart, S., Frege, C., Gordon, H., Hoyle, C. R., Kristensen, T. B., Steiner, G., McPherson Donahue, N., Flagan, R., Gallagher, M. W., Kirkby, J., Möhler, O., Saathoff, H., Schnaiter, M., Stratmann, F., and Tomé, A.: Phase transition observations and discrimination of small cloud particles by light polarization in expansion chamber experiments, Atmos. Chem. Phys., 16, 3651-3664, doi:10.5194/acp-16-3651-2016, 2016.

Nicolet, M., Stetzer, O., Lüönd, F., Möhler, O., and Lohmann, U.: Single ice crystal measurements during nucleation experiments with the depolarization detector IODE, Atmos. Chem. Phys., 10, 313-325, doi:10.5194/acp-10-313-2010, 2010.

Parzen, E.: On Estimation of a Probability Density Function and Mode, Ann. Math. Stat., 33, 1065-1076, doi:10.1214/aoms/1177704472, 1962.

Pruppacher, H. R. and Klett, J. D.: Microphysics of Clouds and Precipitation, Atmospheric and oceanographic sciences library, Kluwer Academic Publishers, Dordrecht, the Netherlands, 2nd Edn., 1997.

Richardson, M.: Making real time measurements of ice nuclei concentrations at upper tropospheric temperatures: Extending the capabilities of the continuous flow diffusion chamber, Dissertation thesis, 268 pp., Colorado State Univ., Fort Collins, 2009.

Roberts, G. C. and Nenes, A.: A continuous-flow streamwise thermal-gradient $\mathrm{CCN}$ chamber for atmospheric measurements, Aerosol Sci. Tech., 39, 206-221, doi:10.1080/027868290913988, 2005. 
Rogers, D. C.: Development of a continuous flow thermal gradient diffusion chamber for ice nucleation studies, Atmos. Res., 22, 149-181, doi:10.1016/0169-8095(88)90005-1, 1988.

Rogers D. C., DeMott P. J., Kreidenweis S. M., and Chen Y. L.: A continuous-flow diffusion chamber for airborne measurements of ice nuclei. J. Atmos. Ocean Tech. 18, 725-741, doi:10.1175/1520-0426(2001)018<0725:ACFDCF>2.0.CO;2, 2001.

Rosenblatt, M.: Remarks on Some Nonparametric Estimates of a Density Function, Ann. Math. Stat., 27, 832-837, doi:10.1214/aoms/1177728190, 1956

Saito, A., Murakami, M., and Tanaka, T.: Automated ContinuousFlow Thermal-Diffusion-Chamber Type Ice Nucleus Counter, SOLA, 7, 29-32, doi:10.2151/sola.2011-008, 2011.

Salam, A., Lesins, G., and Lohmann, U.: Laboratory study of heterogeneous ice nucleation in deposition mode of montmorillonite mineral dust particles aged with ammonia, sulfur dioxide, and ozone at polluted atmospheric concentrations, Air Qual. Atmos. Health, 1, 135-142, doi:10.1007/s11869-008-0019-6, 2008.

Stetzer, O., Baschek, B., Lüönd, F., and Lohmann, U.: The Zurich Ice Nucleation Chamber (ZINC) - A new instrument to investigate atmospheric ice formation, Aerosol Sci. Technol., 42, 6474, doi:10.1080/02786820701787944, 2008

Stocker, T. F., Qin, D., Plattner, G.-K., Tignor, M., Allen, S. K., Boschung, J., Nauels, A., Xia, Y., Bex, V., and Midgley, P. M. (Eds.): Climate Change 2013: The Physical Science Basis, Working Group I Contribution to the Fifth Assessment Report of the Intergovernmental Panel on Climate Change, Summary for Policymakers (IPCC, 2013), Cambridge, United Kingdom and New York, NY, USA, 2013.
Storelvmo, T., Hoose, C., and Eriksson, P.: Global modeling of mixed-phase clouds: The albedo and lifetime effects of aerosols, J. Geophys. Res., 116, D05207, doi:10.1029/2010JD014724, 2011.

Tao, W.-K., Chen, J.-P., Li, Z., Wang, C., and Zhang, C.: Impact of aerosols on convective clouds and precipitation, Rev. Geophys., 50, RG2001, doi:10.1029/2011RG000369, 2012.

Thomson, E. S., Wilen, L. A., and Wettlaufer, J. S.: Light scattering from an isotropic layer between uniaxial crystals, J. Phys.-Condens. Mat., 21, 195407, doi:10.1088/09538984/21/19/195407, 2009.

Welti, A., Lüönd, F., Stetzer, O., and Lohmann, U.: Influence of particle size on the ice nucleating ability of mineral dusts, Atmos. Chem. Phys., 9, 6705-6715, doi:10.5194/acp-9-6705-2009, 2009.

Welti, A., Kanji, Z. A., Lüönd, F., Stetzer, O., and Lohmann, U.: Exploring the Mechanisms of Ice Nucleation on Kaolinite: From Deposition Nucleation to Condensation Freezing, J. Atmos. Sci., 71, 16-36, doi:10.1175/JAS-D-12-0252.1, 2014.

Wettlaufer, J. S., Dash, J. G., and Untersteiner, N. (Eds.): Ice Physics and the Natural Environment, vol. 56 of NATO ASI Series I, Springer-Verlag, Heidelberg, 1999. 